\title{
Rüzgâr Hızı Haritalarının Oluşturulmasında Kullanılan Enterpolasyon Yöntemlerinin Karşılaştırılması: Balıkesir Örneği
}

\author{
Selim Serhan YILDIZ ${ }^{1}$ \\ ${ }^{1}$ Osmaniye Korkut Ata Üniversitesi, Mühendislik Fakültesi, Harita Mühendisliği Bölümü, Osmaniye. \\ e-posta: serhan@osmaniye.edu.tr ORCID ID: https://orcid.org/0000-0001-6221-7035 \\ Geliş Tarihi: 21.01.2021 Kabul Tarihi: 23.02.2021
}

Öz

Dünyada artan enerji ihtiyacıyla beraber yenilenebilir enerji kaynaklarına olan talep de gün geçtikçe artmaktadır. Enerji ihtiyacındaki bu artış, devletleri ve özel sektör yatırımcılarını yenilenebilir enerji kaynaklarına yönlendirmektedir. Yeryüzündeki en önemli yenilenebilir enerji kaynaklarından biri de rüzgâr enerjisidir. Son yıllarda rüzgâr enerjisinin yenilenebilir enerji kaynakları ile üretilen enerji miktarındaki payı artmaktadır. Bu artışta rüzgâr enerjisinin çevre dostu olması ve kendini

Anahtar kelimeler Rüzgâr Hızı; Enterpolasyon; Balıkesir; RES yenileyebilmesi gibi özellikleri sayesinde sürdürülebilir bir enerji kaynağı olmasının etkisi büyüktür. Bu anlamda, rüzgâr enerjisinden en yüksek verimi alabilmek için santrallerin doğru konumlandırıması başka bir ifade ile santral yer seçimi hususu büyük öneme sahiptir. Rüzgâr enerji santrallerinin yer seçiminde literatürdeki en önemli parametrelerden biri rüzgâr enerjisi kaynağı ve buna bağlı olarak rüzgâr hızıdır. Rüzgâr hızı haritalarının oluşturulabilmesi için belirli sayıda istasyondan elde edilen noktasal hız verilerinin çalışma alanına yayılması gerekmektedir. Bu çalışmada, Balıkesir ilinde yer alan 32 adet meteoroloji istasyonundan elde edilen rüzgâr hızı verileri yardımıyla Balıkesir ili sınırları içinde IDW, Kriging, Natural Neighbor, Spline ve Trend olmak üzere beş farklı enterpolasyon yöntemi ile rüzgâr hızı haritaları oluşturulmuş ve kullanılan enterpolasyon yöntemleri karesel ortalama hata değerlerine göre karşılaştırılmıştır.

\section{A Comparison of Interpolation Methods in Creation of Wind Speed Maps: A Case Study of Balıkesir}

\begin{abstract}
With the increasing need for energy in the world, the demand for renewable energy sources is increasing day by day. This increase in energy need directs governments and private sector investors to renewable energy sources. Wind energy is one of the most important renewable energy resources on earth. In recent years, the share of wind energy in the amount of energy produced by renewable energy sources has been increasing. Wind energy emerges as a sustainable energy source due to its environmental friendliness and ability to renew itself. These features of wind energy have a great effect on the increase of its share in the energy sector. In order to get the highest efficiency from wind energy, the correct positioning of wind farms, that is, the concept of site selection is very important. One of the most important parameters in site selection of wind farms is the wind energy source and the wind speed accordingly. In order to create wind speed maps, wind speed data obtained from a certain number of stations should be interpolated for the study area. In this study, wind speed data obtained from 32 meteorology stations in Balıkesir province were used. With the help of these data, wind velocity maps were created with five different interpolation methods, namely IDW, Kriging, Natural Neighbor, Spline and Trend, within the borders of Balıkesir province. Finally, the results obtained by these five methods were compared with the real wind speed values according to root mean square error and evaluations were made.
\end{abstract}




\section{Giriş}

Rüzgâr enerjisi, artan enerji ihtiyacı ve fosil yakıtların hızla azalmasından dolayı önemi gittikçe artan bir yenilenebilir enerji kaynağı olmuştur. Rüzgâr enerjisi potansiyeli yüksek alanlarda kurulacak rüzgâr enerji santralleri, çevresel anlamda temiz ve elektrik üretiminde verimlidir. Rüzgâr enerji potansiyeli ise rüzgâr hızı ile doğru orantılıdır. Dolayısıyla rüzgâr hızının enerji üretimi için uygunluğunun artması aynı zamanda verimliliği de artırmaktadır. Türkiye rüzgâr enerjisi potansiyel atlası (REPA-V1) verileri incelendiğinde rüzgâr hızlarının yüksek olduğu yerlerde rüzgâr enerji potansiyelinin de yüksek olduğu görülmektedir. Yine REPA-V1 verilerine göre $50 \mathrm{~m}$ yükseklikte ve $7 \mathrm{~m} / \mathrm{s}^{\prime}$ nin üzerinde yıllık ortalama rüzgâr hızına sahip kullanılabilir alanlardaki toplam enerji potansiyeli $47849.44 \mathrm{MW}$ olarak ifade edilmiştir (Int Kyn. 1). Güncel rüzgâr türbin teknolojisinde kule yüksekliklerinin 50 m'den daha yüksek olduğu dikkate alındığında bu potansiyelin daha da artması beklenmektedir. 2020 yılı Temmuz ayı itibariyle Türkiye'deki toplam kurulu güç $8288 \mathrm{MW}$ olmuştur (TUREB 2020). Buna göre toplam kurulu güç, toplam potansiyelin sadece \% 17.3'üne karşılık gelmektedir. Ayrıca, 2020 yılının ilk yarısında Türkiye'de rüzgâr kaynaklı üretilen elektriğin toplam elektrik üretimindeki payı ortalama \% 8.52 olarak gerçekleşmiştir (TUREB 2020).

Rüzgâr enerjisinden etkin olarak yararlanabilmesi için, enerji santrallerinin kurulacağı yerlerin belirli bir rüzgâr potansiyeline sahip olması gerekir. Bu konudaki en önemli parametre hiç şüphesiz rüzgâr hızıdır. İşletme halindeki rüzgâr enerji santralleri göz önünde bulundurulduğunda, santrallerin rüzgâr hızının yüksek olduğu alanlarda kuruldukları görülmektedir. Ayrıca, literatürdeki rüzgâr enerji santralleri için en uygun yer belirleme çalışmaları incelendiğinde, değerlendirmeye alınan en önemli parametrenin rüzgâr hızı olduğu görülmektedir (Parry and Baban 2001, Krewitt and Nitsch 2003, Moradi et al. 2020).

Bu çalışmada 32 adet meteoroloji istasyonundan noktasal bazda elde edilen rüzgâr hızlarının, Inverse Distance Weighting (IDW), Kriging, Natural Neighbor, Spline ve Trend enterpolasyon yöntemleri kullanılarak Balıkesir iline ait $50 \mathrm{~m}$ yükseklikteki rüzgâr hızı haritaları elde edilmiştir. Bu kapsamda noktasal olan rüzgâr hızı değerleri kullanılarak il geneline yayılmış raster formatında haritalar üretilmiştir. Rüzgâr hızı haritalarının üretilmesinin ardından her bir istasyonun enterpolasyon sonucu elde edilen hız değeri ile gerçek hız değeri karşılaştırılarak kullanılan enterpolasyon yöntemleri doğruluk yönünden değerlendirilmiştir.

\section{Rüzgâr Hızı Haritalarının Hazırlanması}

Rüzgâr enerji santrallerin kurulmasında dikkate alınması gereken faktörlerden en önemlisi rüzgâr hızıdır. Rüzgâr hızlarının alansal dağılımının elde edilmesi rüzgâr türbinlerinin yerlerinin belirlenmesinde büyük bir role sahiptir. Bu nedenle, nokta bazlı olarak ölçülen rüzgâr hızlarının çalışma alanının tamamını kapsayacak şekilde elde edilmesi yani rüzgâr hızı haritalarının hazırlanması gerekmektedir. Yıldız 2021'de detaylı olarak anlatılan nokta bazlı rüzgâr hızları kullanılarak rüzgâr hızı haritalarının hazırlanması işleminde öncelikli olarak rüzgâr hızı haritalarının referans yüksekliğinin belirlenmesi gerekmektedir. Başka bir ifade ile, harita yer alacak rüzgâr hızlarının hangi yükseklikteki hızlar olacağının belirli olması gereklidir. Bunun için, ölçülen rüzgâr hızı ölçme yapılan istasyondaki sensör yüksekliğinden rüzgâr haritası oluşturulması istenen yüksekliğe taşınmalıdır. Daha sonra mekânsal enterpolasyon yöntemleri kullanılarak nokta bazlı rüzgâr hızlarından rüzgâr hızı haritaları üretilmelidir.

\subsection{Enterpolasyon Yöntemleri}

Mekansal enterpolasyon işlemi basitçe; ayrık noktaların veya alt alanların bir dizi mekansal veri olarak verildiği durumlarda, tüm yüzeyi en iyi şekilde temsil edebilecek ve diğer noktalardaki veya alt alanlardaki değerleri en iyi şekilde tahmin edecek işlev olarak tanımlanabilir (Lam 1983).

Bu çalışmada, uygulamada sıklıkla kullanılan beş farklı enterpolasyon yöntemi kullanılmıştır. Bunlar;

- IDW

- Kriging

- Natural Neighbor 
- Spline

- Trend

yöntemleridir.

IDW, mesafeye bağı ığırlıklandırma yaparak etki analizi gerçekleştiren bir yöntemdir. Bu yöntemde, mesafenin artması ağırlık değerini düşürmektedir. Denklem 1 IDW yönteminde kullanılan hesaplamayı göstermektedir (Luo et al. 2008).

$\hat{Z}\left(\mathrm{~s}_{0}\right)=\left[\sum_{i=1}^{n} w\left(d_{i}\right) Z\left(s_{i}\right)\right] /\left[\sum_{i=1}^{n} w\left(d_{i}\right)\right]$

Denklem $1^{\prime}$ de $\hat{Z}\left(s_{0}\right)$ ve $Z\left(s_{i}\right)$, $s_{0}$ ve $s_{\mathrm{i}}$ konumlarında tahmin edilen ve gözlenen değerleri, $N$ tahminde kullanılan örnek nokta sayısını, $w$ ağırlık fonksiyonunu, $d_{i}$ ise $s_{0}$ ve $s_{\mathrm{i}}$ arasındaki mesafeyi ifade etmektedir.

Kriging Yöntemi, IDW yöntemine benzer bir şekilde bilinmeyen noktalardaki değer kestirimi için değeri bilinen noktalarda ağırlıkların lineer kombinasyonunu kullanan stokastik bir yöntemdir (Luo et al. 2008). Ayrıca Kriging yöntemi, istatistiksel olmayan yöntemlerin aksine yüzey tahminlerinin oluşturulmasında mekansal ilişkileri kullanır. Kriging yönteminin genel eşitliği Denklem 2'de verilmiştir (Gonzalez-Longatt et al. 2015).

$\hat{Z}\left(\mathrm{x}_{0}\right)=\sum_{i=1}^{n} \lambda_{i} z\left(x_{i}\right)$

2 nolu denklemde; $z\left(x_{i}\right) z$ değişkeninin $x_{1}, x_{2}, \ldots, x_{n}$ noktalarındaki gözlenen değerlerini, $\lambda_{i}$ ise ağırlıkları göstermektedir.

Natural Neighbor Yöntemi, IDW yöntemine benzer bir şekilde mesafeye bağlı ağırlıklandırma uygulamaktadır. Değeri hesaplanmak istenen noktaya en yakın değeri bilinen noktalar kümesi bulunur ve bu noktalara ağırlıklar orantılı alanlar temelinde uygulanarak yüzey değerleri hesaplanır (Bobach 2008, Doğru vd. 2011).

Spline Yöntemi, üç boyutlu yüzeyler üzerindeki iki boyutlu eğrileri temsil eden deterministik bir enterpolasyon tekniğidir (Luo et al. 2008). Özellikle sayısal yükseklik modelleri oluşturmak için yüksekliklerin enterpolasyonunda kullanılan özel bir alt sınıfı olan Thin Plate Spline (TPS) yöntemi sıklıkla kullanılan bir yöntemdir (Luo et al. 2008). Spline, nokta bazlı girdi verilerinden eğriliğin minimum olduğu bir yüzey geçirerek değerleri tahmin eder.
Trend Yöntemi, en küçük kareler regresyonu kullanarak örnek noktalarına uyan yüzeyi bulan istatistiksel bir yöntemdir (Luo et al. 2008). Tüm yüzey için bir polinom denklemi uyumu sağlanır. Bu, girdi değerlerine göre yüzey değişimini en aza indiren bir yüzeyle sonuçlanır. Yüzey, her giriş noktası için, gerçek değerler ile tahmini değerler arasındaki farkların toplamı (varyans) mümkün olduğunca küçük olacak şekilde inşa edilmiştir.

\section{Uygulama}

Çalışmanın ana amacını oluşturan rüzgâr hızı haritalarının oluşturulmasında kullanılabilecek en uygun mekânsal enterpolasyon yönteminin belirlenebilmesi için Balıkesir ilinde yer alan meteoroloji istasyonlarında $10 \mathrm{~m}$ yükseklikte gerçekleştirilen ölçmeler ile elde edilen nokta bazlı rüzgâr hızı verileri kullanılmıştır. Çalışma kapsamında, enterpolasyon işlemi 5 farklı yöntem kullanılarak gerçekleştirilmiştir. Çalışma alanının coğrafi konumu ve ilçe sınırları Şekil 1'de verilmiştir.

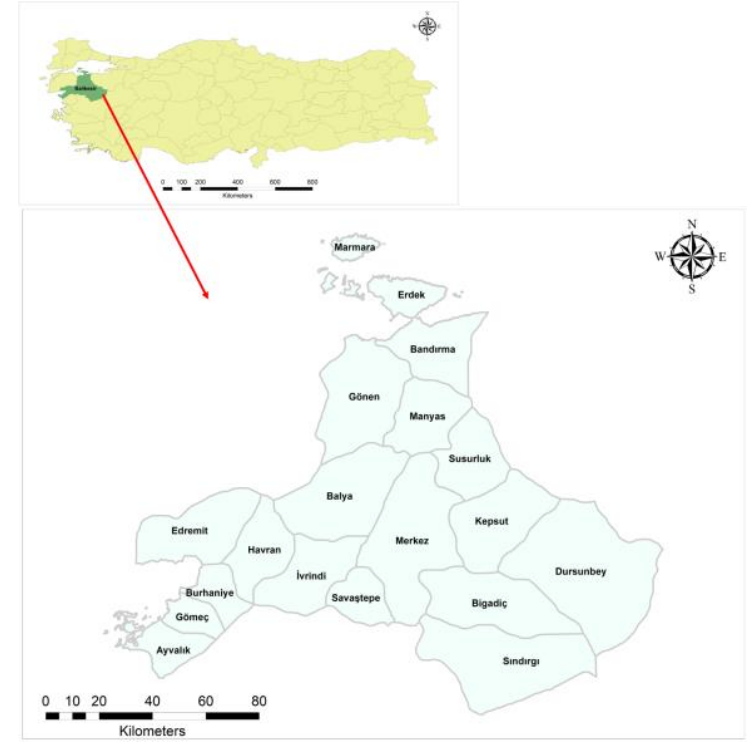

Şekil 1. Balıkesir ilinin Türkiye'deki konumu ve ilçe sınırları.

Balıkesir il sınırları içerisinde bulunan 32 adet meteoroloji istasyonunun 2014-2019 yılları arasındaki 10 m yükseklikte ölçülen günlük ortalama hız değerleri Meteoroloji Genel Müdürlüğü'nden (MGM) temin edilmiştir. Çalışmada kullanılan istasyonların coğrafi dağılımı Şekil 2'de verilmiştir. 


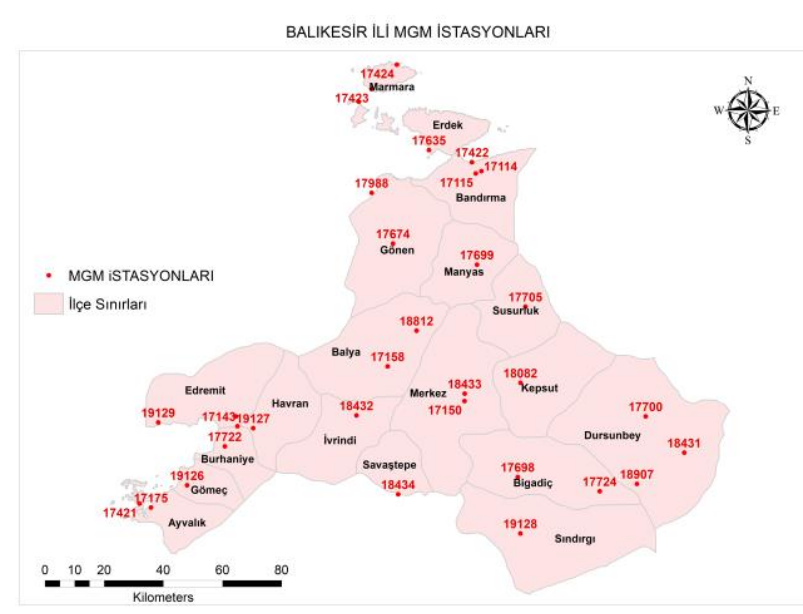

Şekil 2. Balıkesir ilinde yer alan MGM istasyonları.

Ilk olarak, bu istasyonların hız değerleri 3 nolu Hellmann eşitliği kullanılarak $10 \mathrm{~m}$ yükseklikten 50 m yüksekliğe taşınmıştır (Çizelge 1). Bu işlem, istasyonların yer aldığı yüzeyin pürüzlülüğü ve hızın taşınmak istendiği yükseklik değerine bağlı olarak gerçekleştirilmektedir (Tar 2008).

$\frac{V}{V_{0}}=\left(\frac{H}{H_{0}}\right)^{\alpha}$

3 nolu denklemde, $V_{0}$ ilk hız değerini $(\mathrm{m} / \mathrm{s}), V$ taşınacak yükseklikteki rüzgâr hızını $(\mathrm{m} / \mathrm{s}), H$ rüzgâr hızının taşınmak istendiği yüksekliği (m), $\alpha$ ise rüzgâr hızı ölçümü gerçekleştirilmiş olan istasyondaki yüzeyin pürüzlülüğüne göre belirlenen sürtünme katsayısını göstermektedir. $H_{0}$ ise ölçümün yapıldığı yüksekliği $(m)$ göstermektedir.

Çizelge 1. 32 adet MGM istasyonunun 50 m yükseklikteki ortalama hız değerleri.

\begin{tabular}{cccccccc}
\hline isT. ID & $\begin{array}{c}\text { HIz } \\
(\mathbf{m} / \mathrm{s})\end{array}$ & isT. ID & $\begin{array}{c}\text { HIz } \\
(\mathbf{m} / \mathrm{s})\end{array}$ & isT. ID & $\begin{array}{c}\text { HIz } \\
(\mathbf{m} / \mathrm{s})\end{array}$ & isT. ID & $\begin{array}{c}\text { HIz } \\
(\mathbf{m} / \mathrm{s})\end{array}$ \\
\hline $\mathbf{1 7 4 2 1}$ & 6.332 & $\mathbf{1 7 1 1 5}$ & 8.201 & $\mathbf{1 8 4 3 1}$ & 2.118 & $\mathbf{1 8 4 3 2}$ & 3.925 \\
\hline $\mathbf{1 7 1 7 5}$ & 3.404 & $\mathbf{1 7 4 2 2}$ & 7.942 & $\mathbf{1 7 1 4 5}$ & 3.799 & $\mathbf{1 8 0 8 2}$ & 3.743 \\
\hline $\mathbf{1 7 1 5 0}$ & 4.581 & $\mathbf{1 7 1 1 4}$ & 6.555 & $\mathbf{1 9 1 2 9}$ & 2.997 & $\mathbf{1 7 6 9 9}$ & 4.520 \\
\hline $\mathbf{1 7 1 4 3}$ & 8.166 & $\mathbf{1 7 6 9 8}$ & 5.197 & $\mathbf{1 7 6 3 5}$ & 4.846 & $\mathbf{1 7 4 2 3}$ & 6.081 \\
\hline $\mathbf{1 8 4 3 3}$ & 4.309 & $\mathbf{1 7 7 2 4}$ & 2.393 & $\mathbf{1 7 3 8 2}$ & 6.352 & $\mathbf{1 7 4 2 4}$ & 6.484 \\
\hline $\mathbf{1 7 1 5 8}$ & 9.171 & $\mathbf{1 8 9 0 7}$ & 5.931 & $\mathbf{1 9 1 2 6}$ & 4.738 & $\mathbf{1 8 4 3 4}$ & 4.353 \\
\hline $\mathbf{1 7 6 7 4}$ & 3.272 & $\mathbf{1 7 7 2 2}$ & 5.195 & $\mathbf{1 7 9 8 8}$ & 5.380 & $\mathbf{1 9 1 2 8}$ & 2.578 \\
\hline $\mathbf{1 8 8 1 2}$ & 3.185 & $\mathbf{1 7 7 0 0}$ & 2.871 & $\mathbf{1 9 1 2 7}$ & 6.400 & $\mathbf{1 7 7 0 5}$ & 4.900 \\
\hline & & & & & & & \\
\hline
\end{tabular}

Bununla birlikte, beş farklı yöntemle oluşturulan yüzey haritalarından elde edilen MGM istasyonlarına ait rüzgâr hızı değerleri, bu istasyonların girdi verisi olarak kullanılan ortalama hız değerleri ile karşılaştııılmıştır. Karesel Ortalama Hata $(\mathrm{KOH})$ değerleri izleyen eşitlikle hesaplanmıştır.
$\mathrm{KOH}=\frac{1}{\sqrt{n}} \sqrt{\sum_{1}^{n}\left[\hat{z}\left(s_{i}\right)-z\left(s_{i}\right)\right]^{2}}$

4 nolu denklemde, $\hat{Z}\left(s_{i}\right)$ her bir istasyon için enterpolasyon işlemi ile tahmini gerçekleştirilen rüzgâr hızı değerini, $z\left(s_{i}\right)$ ise enterpolasyon işleminde girdi olarak kullanılan istasyondaki rüzgâr hızı değerini, $n$ ise toplam istasyon sayısını ifade etmektedir.

\section{Bulgular ve Tartışma}

Bu çalışma kapsamında, noktasal rüzgâr hızı değerlerinin Balıkesir ili için beş farklı enterpolasyon yöntemi kullanılarak rüzgâr hızı haritalarının oluşturulmuştur. IDW enterpolasyon yöntemi ile oluşturulan ve Yıldız 2021'de de yer alan rüzgâr hızı haritası Şekil 3'te verilmiştir. Kriging, Natural Neighbor, Spline ve Trend enterpolasyon yöntemleri ile oluşturulan haritalar ise sırasıyla Şekil $4 a, b, c$, d'de gösterilmiştir. Rüzgâr hızı haritalarının oluşturulması ile kestirimi yapılan hız değerleri ve bu kestirimlere dair doğruluk analizi sonuçları elde edilmiştir.

Gerçekleştirilen enterpolasyon işlemleri sonucunda elde edilen hız değerleri Çizelge 2'de ve bu değerlerin Hellmann eşitliği ile hesaplanan değerlerden olan farkları ve farklar kullanılarak hesaplanan $\mathrm{KOH}$ değerleri Çizelge 3'te verilmiştir. Her bir enterpolasyon yöntemi için hesaplanan $\mathrm{KOH}$ değerleri çizelgenin en alt kısmında gösterilmektedir.

Meteoroloji istasyonlarında gerçekleştirilen rüzgâr hızı ölçmelerindeki hassasiyet $\mathrm{dm} / \mathrm{s}$ mertebesindedir. Ancak, rüzgâr hızı haritalarının oluşturulmasında istasyonlarda ölçülen hız değerlerinin ortalamalarının kullanılıyor olması ve enterpolasyon işlemi sonucunda elde edilen hız değerlerinin girdi değerleri ile daha hassas bir şekilde karşılaştırılabilmesi için rüzgâr hızı değerleri $\mathrm{mm} / \mathrm{s}$ hassasiyette ele alınmıştır. 
Çizelge 2. İstasyon noktalarında ölçülen ve farklı enterpolasyon yöntemlerinden hesaplanan rüzgâr hızları.

\begin{tabular}{|c|c|c|c|c|c|c|}
\hline \multirow[b]{2}{*}{ isT. ID } & \multirow{2}{*}{$\begin{array}{c}\text { MGM } \\
\text { Ort. Hiz } \\
(\mathrm{m} / \mathrm{s})\end{array}$} & \multicolumn{5}{|c|}{ Enterpolasyon Yöntemlerinden Elde Edilen Hızlar } \\
\hline & & IDW & Kriging & $\begin{array}{l}\text { Natural } \\
\text { Neighbor }\end{array}$ & Spline & Trend \\
\hline 17421 & 6.332 & 6.309 & 5.189 & 6.272 & 6.440 & 4.930 \\
\hline 17175 & 3.404 & 3.402 & 4.710 & 3.478 & 3.414 & 4.866 \\
\hline 17150 & 4.581 & 4.580 & 4.437 & 4.576 & 4.574 & 4.519 \\
\hline 17143 & 8.166 & 8.169 & 5.905 & 8.080 & 8.163 & 5.070 \\
\hline 18433 & 4.309 & 4.310 & 4.447 & 4.321 & 4.313 & 4.560 \\
\hline 17158 & 9.171 & 9.170 & 6.302 & 9.159 & 9.175 & 4.954 \\
\hline 17674 & 3.272 & 3.270 & 4.821 & 3.281 & 3.260 & 5.647 \\
\hline 18812 & 3.185 & 3.190 & 4.351 & 3.212 & 3.165 & 5.074 \\
\hline 17115 & 8.201 & 8.199 & 6.738 & 8.174 & 8.190 & 5.800 \\
\hline 17422 & 7.942 & 7.905 & 6.692 & 7.923 & 8.109 & 5.867 \\
\hline 17114 & 6.555 & 6.564 & 6.557 & 6.554 & 6.485 & 5.795 \\
\hline 17698 & 5.197 & 5.200 & 4.653 & 5.192 & 5.198 & 3.914 \\
\hline 17724 & 2.393 & 2.390 & 3.354 & 2.453 & 2.400 & 3.579 \\
\hline 18907 & 5.931 & 5.930 & 4.548 & 5.890 & 5.923 & 3.511 \\
\hline 17722 & 5.195 & 5.200 & 5.327 & 5.207 & 5.213 & 4.992 \\
\hline 17700 & 2.871 & 2.870 & 3.488 & 2.873 & 2.866 & 3.874 \\
\hline 18431 & 2.118 & 2.122 & 3.292 & 2.173 & 2.141 & 3.544 \\
\hline 17145 & 3.799 & 3.806 & 5.263 & 3.818 & 3.739 & 5.132 \\
\hline 19129 & 2.997 & 3.000 & 4.298 & 3.014 & 3.021 & 5.334 \\
\hline 17635 & 4.846 & 4.850 & 5.238 & 4.866 & 4.865 & 6.077 \\
\hline 17382 & 6.352 & 6.346 & 5.804 & 6.340 & 6.391 & 6.584 \\
\hline 19126 & 4.738 & 4.740 & 4.906 & 4.727 & 4.735 & 4.882 \\
\hline 17988 & 5.380 & 5.378 & 5.687 & 5.373 & 5.321 & 5.991 \\
\hline 19127 & 6.400 & 6.400 & 5.746 & 6.374 & 6.352 & 5.011 \\
\hline 18432 & 3.925 & 3.920 & 4.663 & 3.928 & 3.900 & 4.766 \\
\hline 18082 & 3.743 & 3.740 & 4.193 & 3.741 & 3.736 & 4.449 \\
\hline 17699 & 4.520 & 4.520 & 5.024 & 4.521 & 4.522 & 5.269 \\
\hline 17423 & 6.081 & 6.080 & 5.798 & 6.083 & 6.080 & 6.609 \\
\hline 17424 & 6.484 & 6.480 & 5.827 & 6.471 & 6.469 & 6.670 \\
\hline 18434 & 4.353 & 4.351 & 4.685 & 4.348 & 4.361 & 4.189 \\
\hline 19128 & 2.578 & 2.580 & 3.651 & 2.582 & 2.586 & 3.581 \\
\hline 17705 & 4.900 & 4.900 & 5.018 & 4.900 & 4.901 & 4.876 \\
\hline
\end{tabular}

Çizelge 3. Enterpolasyon sonucunda elde edilen farklar ve karesel ortalama hata değerleri.

\begin{tabular}{|c|c|c|c|c|c|}
\hline \multirow{2}{*}{ IST. ID } & \multicolumn{5}{|c|}{$\begin{array}{l}\text { Enterpolasyon Yöntemlerinden Elde Edilen Farklar } \\
\qquad(\mathrm{m} / \mathrm{s})\end{array}$} \\
\hline & IDW & Kriging & $\begin{array}{l}\text { Natural } \\
\text { Neighbor }\end{array}$ & Spline & Trend \\
\hline 17421 & 0.023 & 1.143 & 0.060 & -0.108 & 1.402 \\
\hline 17175 & 0.002 & -1.306 & -0.074 & -0.010 & -1.462 \\
\hline 17150 & 0.001 & 0.144 & 0.005 & 0.007 & 0.062 \\
\hline 17143 & -0.003 & 2.261 & 0.086 & 0.003 & 3.096 \\
\hline 18433 & -0.001 & -0.137 & -0.011 & -0.004 & -0.251 \\
\hline 17158 & 0.001 & 2.869 & 0.012 & -0.004 & 4.217 \\
\hline 17674 & 0.002 & -1.549 & -0.010 & 0.011 & -2.375 \\
\hline 18812 & -0.005 & -1.166 & -0.026 & 0.021 & -1.889 \\
\hline 17115 & 0.001 & 1.463 & 0.026 & 0.011 & 2.401 \\
\hline 17422 & 0.037 & 1.250 & 0.019 & -0.167 & 2.075 \\
\hline 17114 & -0.009 & -0.001 & 0.001 & 0.070 & 0.760 \\
\hline 17698 & -0.003 & 0.544 & 0.005 & 0.000 & 1.283 \\
\hline 17724 & 0.002 & -0.961 & -0.061 & -0.008 & -1.187 \\
\hline 18907 & 0.002 & 1.384 & 0.041 & 0.009 & 2.420 \\
\hline 17722 & -0.005 & -0.132 & -0.012 & -0.018 & 0.203 \\
\hline 17700 & 0.001 & -0.617 & -0.002 & 0.005 & -1.003 \\
\hline 18431 & -0.004 & -1.174 & -0.055 & -0.024 & -1.426 \\
\hline 17145 & -0.006 & -1.464 & -0.018 & 0.061 & -1.332 \\
\hline 19129 & -0.003 & -1.301 & -0.017 & -0.024 & -2.337 \\
\hline 17635 & -0.004 & -0.392 & -0.021 & -0.019 & -1.231 \\
\hline 17382 & 0.006 & 0.548 & 0.012 & -0.039 & -0.232 \\
\hline 19126 & -0.002 & -0.168 & 0.010 & 0.003 & -0.144 \\
\hline 17988 & 0.002 & -0.307 & 0.007 & 0.059 & -0.611 \\
\hline 19127 & 0.000 & 0.653 & 0.025 & 0.048 & 1.389 \\
\hline 18432 & 0.004 & -0.739 & -0.003 & 0.025 & -0.842 \\
\hline 18082 & 0.003 & -0.450 & 0.002 & 0.007 & -0.707 \\
\hline 17699 & 0.000 & -0.504 & -0.002 & -0.002 & -0.749 \\
\hline 17423 & 0.001 & 0.283 & -0.001 & 0.002 & -0.528 \\
\hline 17424 & 0.005 & 0.658 & 0.013 & 0.015 & -0.186 \\
\hline 18434 & 0.003 & -0.332 & 0.005 & -0.008 & 0.164 \\
\hline 19128 & -0.002 & -1.072 & -0.003 & -0.007 & -1.003 \\
\hline 17705 & 0.000 & -0.118 & -0.001 & -0.001 & 0.023 \\
\hline $\mathrm{KOH}$ & 0.008 & 1.066 & 0.030 & 0.043 & 1.558 \\
\hline
\end{tabular}


BALIKESIR ILI RÜZGAR HIZI HARITASI (IDW)

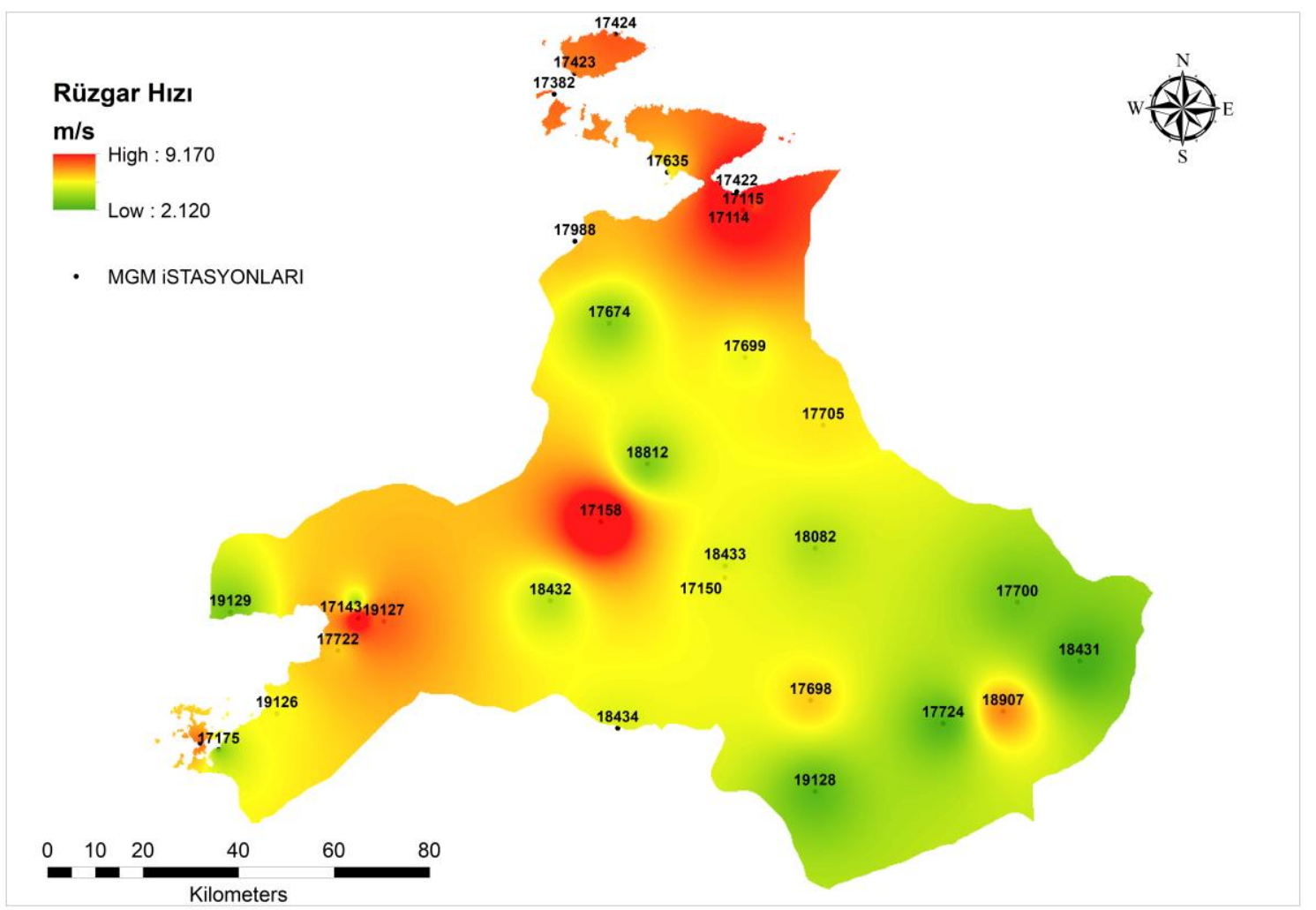

Şekil 3. IDW yöntemi kullanılarak üretilen Balıkesir iline ait 50 m yükseklikteki rüzgâr hızı haritası (Yıldız, 2021).

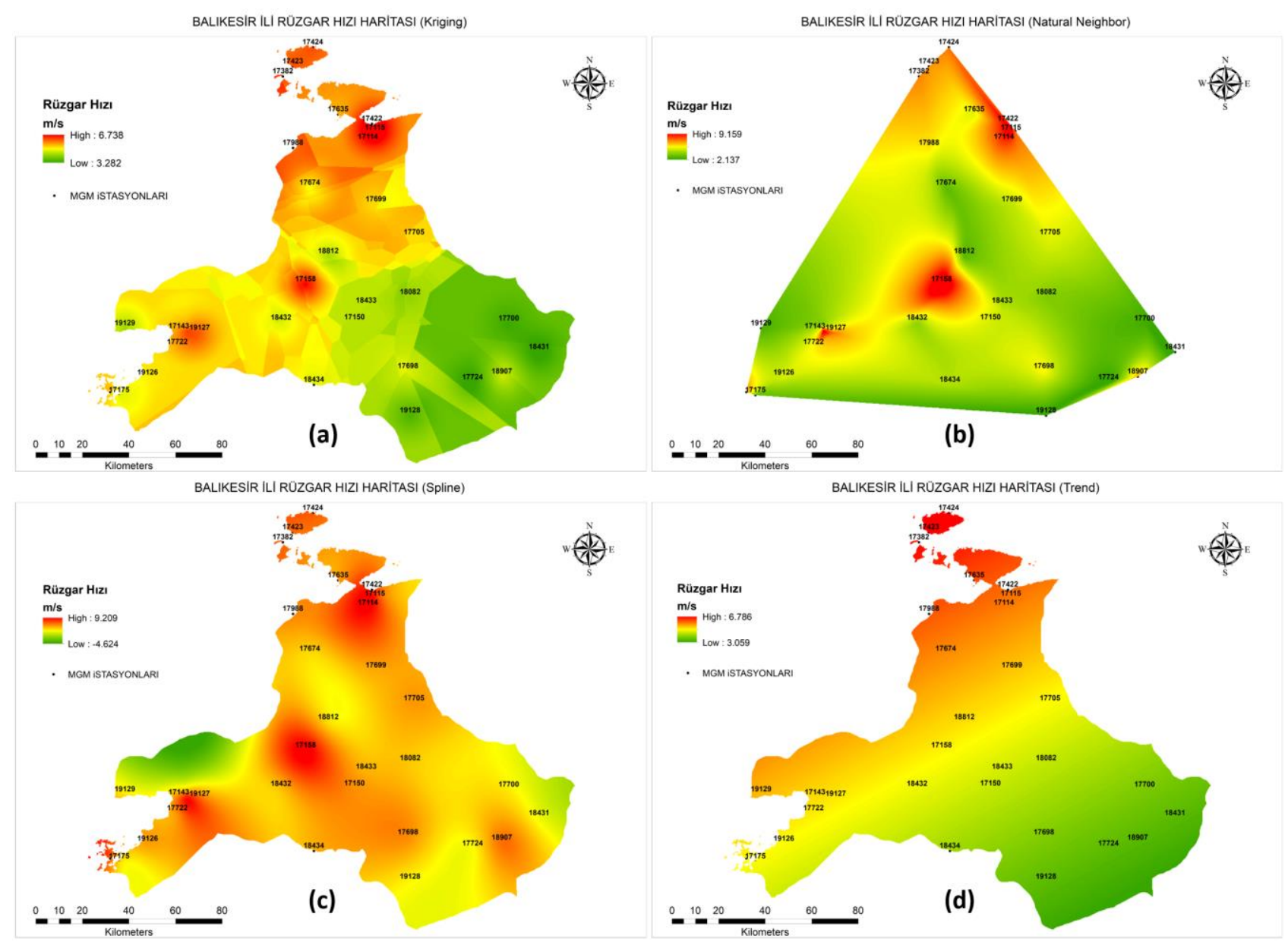

Şekil 4. Balıkesir iline ait 50 m yükseklikteki rüzgâr hızı haritası (a) Kriging, (b) Natural Neighbor, (c) Spline ve (d) Trend yöntemi. 
Luo et al. (2008), Ackere et al. (2015) ve Doğru vd. (2011) tarafından gerçekleştirilen ve rüzgâr hızı haritalarının üretimi için farklı enterpolasyon yöntemlerinin karşılaştırıldı̆̆ı çalışmalarda elde edilen $\mathrm{KOH}$ değerleri Çizelge 4'te verilmiştir. Luo et al. (2008) ve Doğru vd. (2011)'de en düşük KOH değerine sahip yöntem Kriging yöntemi olmakla birlikte IDW yöntemi de bu yönteme yakın sonuçlara sahiptir. Ackere et al. (2015)'te ise en düşük $\mathrm{KOH}$ değerine sahip yöntem bu çalışmada olduğu gibi IDW olarak ortaya çıkmıştır.

Çizelge 4. Benzer çalışmalarda elde edilen $\mathrm{KOH}$ değerleri.

\begin{tabular}{cccccc}
\hline & \multicolumn{5}{c}{ Enterpolasyon Yöntemleri ile Elde Edilen KOH } \\
& IDW & Kriging & $\begin{array}{c}\text { Natural } \\
\text { Neighbor }\end{array}$ & Spline & Trend \\
\cline { 2 - 6 } & IDW & - & & 1.89 & 1.93 \\
\hline $\begin{array}{c}\text { (Luo et al. } \\
\text { 2008) }\end{array}$ & 1.74 & 1.61 & - & - & - \\
\hline $\begin{array}{c}\text { (Ackere et al. } \\
\text { 2015) }\end{array}$ & 0.52 & 0.72 & - & - & - \\
\hline $\begin{array}{c}\text { (Doğru vd. } \\
\text { 2011) }\end{array}$ & 0.53 & 0.4910 & 0.5978 & - \\
\hline
\end{tabular}

\section{Sonuçlar}

IDW yöntemi ile elde edilen farklar incelendiğinde, 19127, 17699 ve 17705 nolu istasyonlarda farkın 1 $\mathrm{mm} / \mathrm{s}$ 'nin altında olduğu görülmüştür. En yüksek farkın $0.037 \mathrm{~m} / \mathrm{s}$ ile 17422 nolu istasyona ait olduğu, $0.010 \mathrm{~m} / \mathrm{s}^{\prime}$ nin üzerinde farkın sadece 2 istasyonda ortaya çıktığı ve farkların büyük bir çoğunluğunun $0.010 \mathrm{~m} / \mathrm{s}$ 'nin altında olduğu görülmektedir. Farklardan hesaplanan $\mathrm{KOH}$ değeri $0.008 \mathrm{~m} / \mathrm{s}$ olarak elde edilmiştir.

Kriging yöntemi ile elde edilen sonuçlar incelendiğinde, en yüksek fark $2.869 \mathrm{~m} / \mathrm{s}$ ile 17158 nolu istasyona ait olduğu ve 17114 nolu istasyon hariç diğer tüm istasyonlarda farkların $0.100 \mathrm{~m} / \mathrm{s}^{\prime}$ nin üzerinde olduğu görülmektedir. Farklardan hesaplanan $\mathrm{KOH}$ değeri $1.066 \mathrm{~m} / \mathrm{s}$ olarak elde edilmiştir.

Natural Neighbor yöntemi sonucunda elde edilen farklar incelendiğinde, 17114, 17423 ve 17705 nolu istasyonlarda farkların $1 \mathrm{~mm} / \mathrm{s}$ olduğu ve en yüksek farkın $0.086 \mathrm{~m} / \mathrm{s}$ ile 17143 nolu istasyona ait olduğu görülmektedir. 10 adet istasyonda farkların 0.010 $\mathrm{m} / \mathrm{s}^{\prime}$ nin altında olduğu ve farkların tamamının 0.100 $\mathrm{m} / \mathrm{s}^{\prime}$ nin altında olduğu görülmektedir. Farklardan hesaplanan $\mathrm{KOH}$ değeri $0.030 \mathrm{~m} / \mathrm{s}$ olarak elde edilmiştir.

Spline yöntemi ile elde edilen sonuçlar incelendiğinde, 17698 nolu istasyonda farkın 1 $\mathrm{mm} / \mathrm{s}$ 'nin altında olduğu ve en yüksek farkın ise $0.167 \mathrm{~m} / \mathrm{s}$ ile 17422 nolu istasyona ait olduğu görülmektedir. 13 noktada farkların $0.010 \mathrm{~m} / \mathrm{s}^{\prime}$ nin altında olduğu, 2 noktada ise $0.100 \mathrm{~m} / \mathrm{s}^{\prime}$ nin üzerinde olduğu görülmektedir. Farklardan hesaplanan $\mathrm{KOH}$ değeri $0.043 \mathrm{~m} / \mathrm{s}$ olarak elde edilmiştir.

Trend yöntemi kullanılarak elde edilen farklar incelendiğinde, en küçük farkın 0.023 m/s ile 17705 nolu istasyona ve en yüksek farkın $4.217 \mathrm{~m} / \mathrm{s}$ ile 17158 nolu istasyona ait olduğu ve 18 istasyonda farkların $1 \mathrm{~m} / \mathrm{s}^{\prime}$ nin üzerinde olduğu görülmektedir. Farklar sadece 17150 ve 17705 nolu istasyonlarda $0.010 \mathrm{~m} / \mathrm{s}^{\prime}$ nin altında yer almaktadır. Farklardan hesaplanan $\mathrm{KOH}$ değeri $1.558 \mathrm{~m} / \mathrm{s}$ olarak elde edilmiştir.

Mekansal enterpolasyon yöntemleri elde edilen $\mathrm{KOH}$ değerleri dikkate alınarak karşılaştırıldığında, IDW'nin en düşük hata değerine sahip olan yöntem olduğu ortaya çıkmıştır. Buna göre, Balıkesir ili için rüzgâr hızlarının enterpolasyonunda IDW yönteminin diğer yöntemlere göre daha kullanılabilir olduğu görülmektedir. Sonuç olarak, rüzgâr hızı haritalarının oluşturulmasında kullanılabilecek en uygun mekânsal enterpolasyon yönteminin IDW olduğu söylenebilir.

Bu çalışmada, çok sayıda dayanak noktası kullanarak rüzgâr hızı haritalarının oluşturulmasında en uygun mekânsal enterpolasyon yönteminin belirlenmesi amaçlanmıştır. Bu doğrultuda en sık kullanılan yöntemlerin IDW ve Kriging yöntemleri olduğu görülmekle birlikte, IDW yöntemi kullanılarak daha düşük hata değerleri elde edildiği görülmüştür.

Türkiye'deki rüzgâr enerjisi potansiyeli, toplam kurulu güç miktarı ve rüzgârdan üretilen enerjinin toplam enerji üretimindeki payı dikkate alındığında, rüzgâr enerjisi yatırımlarına oldukça fazla ihtiyaç olduğu bir gerçektir. Bu doğrultuda gerçekleştirilecek olan rüzgâr enerji potansiyeli belirleme ve rüzgâr santralleri için yer belirleme çalışmalarında uygun mekânsal enterpolasyon yöntemi ile üretilmiş rüzgâr hızı haritalarının kullanııması çalışmalara büyük katkı sağlayacaktır.

\section{Kaynaklar}

Ackere, S.V., Eetvelde, G.V., Schillebeeckx, D., Papa, E., Wyngene K.V., Vandevelde, L., 2015. Wind resource mapping using landscape rougness and spatial interpolation methods. Energies, 8, 8682-8703. 
Bobach, T., 2008. Natural Neighbor Interpolation Critical Assessment and New Contributions. PhD thesis, Dem Fachbereich Informatik der Technischen Universitat Kaiserslautern, Kaiserslautern, 215.

Doğru, A.Ö., Keskin, M., Özdoğu, K., İliev, N., Uluğtekin, N.N., Balçık, F.B., Göksel, Ç., Sözen, S., 2011. Meteorolojik verilerin değerlendirilmesi ve sunulması için enterpolasyon yöntemlerinin karşılaştırılması. TMMOB Coğrafi Bilgi Sistemleri Kongresi 2011.

Gonzalez-Longatt, F.G., Medina H., Gonzalez J.S., 2015. Spatial interpolation and orographic correction to estimate wind energy resource in Venezuela. Renewable and Sustainable Energy Reviews, 48, 1-16.

Krewitt, W., Nitsch, J., 2003. The potential for electricity generation from on-shore wind energy under the constraints of nature conservation: a case study for two regions in Germany. Renewable Energy, 28, 16451655.

Lam, N.S., 1983. Spatial Interpolation Methods: A Review. The American Cartographer, 10, 129-150.

Luo, W., Taylor, M.C., Parker, S.R, 2008. A comparison of spatial interpolation methods to estimate continuous wind speed surfaces using irregularly distributed data from England and Wales. International Journal of Climatology, 28, 947-959.

Moradi, S., Yousefi, H., Noorollahi, Y., Rosso, D., 2020. Multi-criteria decision support system for wind farm site selection and sensitivity analysis: case study of Alborz Province, Iran. Energy Strategy Reviews, 29, 100478.

Parry, T., Baban, S., 2001. Developing and applying a GISassisted approach to locating wind farms in the UK. Renewable Energy, 24, 59-71.

Tar, K., 2008. Some statistical characteristics of monthly average wind speed at various heights. Renewable and Sustainable Energy Reviews, 12, 1712-1724.

Türkiye Rüzgar Enerjisi Birliği (TUREB), 2020. Türkiye Rüzgar Enerjisi Istatistik Raporu - Temmuz 2020.

Yıldız, S.S., 2021. Balıkesir ìli Rüzgâr Hızı Haritalarının Hazırlanması ve Rüzgâr Enerjisi Potansiyeli Açısından Incelenmesi. Geomatik, 6(3), 198-206.

\section{internet kaynakları}

1-https://enerji.gov.tr/eigm-yenilenebilir-enerjikaynaklar-ruzgar, (15.02.2021) 